Institute of $\mathbf{F}_{\text {ood and }} \mathbf{A}_{\text {gricultural }} \mathbf{S}_{\text {ciences }}$

\title{
Manual de los Reglamentos del Agua de Florida: Acta del Control de Sustancias Tóxicas 1
}

Michael T. Olexa, Laura Minton, Dulcy Miller, y Sarah Corbett ${ }^{2}$

\section{Agradecimientos}

Los autores agradecen a Richard Budell de la

Oficina de Política del Agua Agrícola del

Departamento de Agricultura y Servicios al

Consumidor de Florida. Los autores también

agradecen a David H. Hammonds, Consultor del

Programa de Salud Ambiental, Oficina de Programas de Aguas de Drenaje en el Sitio, del Departamento de Salud de Florida, y a Edward A. Bettinger, Consultor del Programa de Salud Ambiental, Oficina de Programas de Agua del Departamento de Salud de Florida.

\section{Sinopsis}

El Acta del Control de Sustancias Tóxicas (ACST) de 1976 rige:

- fabricación.

- eliminación.

- exportación.

- distribución.

- procesado de todas las sustancias toxicas.

El ACST exige que tales sustancias químicas sean inspeccionadas y aprobadas por la Agencia de Protección Ambiental (APA) antes que entren al mercado. La APA tiene la opción de restringir el

1. Este es el documento EDIS FE070, una publicación del Department of Food and Resource Economics, Florida Cooperative Extension Service, Institute of Food and Agricultural Sciences, University of Florida, Gainesville, FL. Publicada Noviembre 2002. Por favor visite la página electrónica EDIS en http://edis.ifas.ufl.edu.

2. Michael T. Olexa, es profesor del Department of Food and Resource Economics, Florida Cooperative Extension Service, Institute of Food and Agricultural Sciences, University of Florida, Gainesville, FL; y miembro de Florida Bar; Presidente de Agricultural Law Committee of The Florida Bar; y Director del Agricultural Law Center. Laura Minton, Dulcy Miller, y Sarah Corbett son estudiantes graduadas de Levin College of Law, University of Florida, Gainesville, FL. Filiberto Reyes-Villanueva fue el traductor de la versión en ingles al español.

Esta publicación esta diseñada para proporcionar información precisa, actualizada y autorizada sobre esta material. Sin embargo, ya que las leyes, reglas administrativas y decisiones de la corte, sobre las cuales están basados, están sujetas a revisión constante; algunas partes de esta publicación podrían ser obsoletas en cualquier momento. Esta publicación es distribuida bajo el entendimiento que los autores no están involucrados en ninguna representación legal u otros servicios profesionales, y que la información contenida aquí no debe ser considerada como un substituto de una asesoria legal. Esta publicación no esta completa en proporcionar toda la información para lograr el cumplimiento de las leyes y reglamentos que gobiernan la protección del agua. Por estas razones, el uso de estos manuales por cualquier persona constituye un acuerdo para mantener libre de daño a los autores, al Florida Cooperative Extension Service, al Institute of Food and Agricultural Sciences, y a la University of Florida por cualquier demanda por responsabilidad de daños, o gastos en que pueda incurrir cualquier persona, como un resultado de hacer referencia o confianza sobre la información contenida en esta publicación. Esta publicación fue apoyada financieramente por el Florida Department of Agriculture and Consumer Services.

EI Instituto de Alimentos y Ciencias Agrícolas es Un empleador que opera bajo Acción Afirmativa y provee Oportunidades Igualitarias, dedicado a promocionar la investigación, a información educativa y otros servicios, únicamente a los individuos e instituciones que operan bajo discriminación sin considerar color, raza, sexo, edad, incapacidad u origen. Para más información sobre como obtener otras publicaciones de la extensión, comuníquese con la oficina de Servicio de Extensión de su condado. Servicio de Extensión de la Florida / Instituto de Alimentos y Ciencias Agrícolas / Universidad de la Florida / Christine Taylor Waddill, Decana. 
químico, hacer las pruebas, y obtener datos durante su pre-aprobación para determinar si el químico representa una amenaza a la salud o al medio ambiente.

El ACST no protege lo siguiente:

- los plaguicidas que están cubiertos por la AFIFR.

- tabaco o productos del tabaco.

- ciertos materiales nucleares.

- los químicos que están cubiertos por el Acta de Alimentos, Drogas y Cosméticos.

Todos los otros químicos, si ellos no están ya en la lista aprobada de la APA, están sujetos a revisión antes que sean liberados en el flujo del comercio. El ACST dicta específicamente que la APA crea restricciones para PBC (el único químico identificado por su nombre) como parte del mandato del ACST.

\section{¿Quien Aplica el ACST?}

La APA es la única autoridad para ejecutar el ACST, aunque el ACST específicamente dispone que los estados no están vetados para decretar su propia legislación en la regulación de químicos. El ACST limita el poder del estado solamente al grado que no puede probar nuevos químicos si la APA los esta probando para el mismo propósito, y el estado será restringido para crear requerimientos que sean diferentes de aquellos químicos concernientes de la APA, y que ya han sido regulados por la misma.

\section{¿Cómo es Aplicada la ACST?}

El programa de la APA incluye obtener información acerca del vasto número de químicos existentes, los mas sospechosos están sujetos a requerir pruebas mas extensivas.

Cualquiera que introduce, importe o fabrique un nuevo producto químico debe notificarlo a la APA, como debe hacer cualquiera quien obtenga información la cual implique que un químico representa un riesgo a la salud o al medio ambiente.
Todos los registros, archivos y documentos serán revisados por los inspectores para verificar el cumplimiento.

La APA puede autorizar un amplio rango de restricciones sobre químicos sospechosos incluyendo:

- requerimientos de etiquetado/ advertencia.

- limites de concentración de cantidades elaboradas.

- control de calidad y producción.

- mantenimiento de registros.

- criterio para la eliminación.

El ASCT también da poder a la APA para hacer cumplir sus disposiciones por mandato, ordenes de restricción, inspecciones forzadas y decomiso de un producto así como otros medios. Las cortes también tienen el poder de restringir o usar la fuerza sobre las partes de los productores para hacer cumplir la ASCT. Estos poderes son ampliados con respecto, a los químicos que están identificados como poseedores de un inminente e irracional riesgo de daños serios o de amplia dispersión. También la APA puede exigir la limpieza de las áreas donde las violaciones resultaron en daño al medio ambiente.

\section{¿Cuáles son los Castigos?}

La APA tiene autoridad para imponer multas civiles administrativas de hasta $\$ 25,000$ por cada violación separada del ACST. Cada día de violación continua representa una violación separada. También, los violadores intencionados o los conocedores están sujetos a castigos criminales de hasta $\$ 25,000$ por día por violación y hasta un año en prisión.

\section{Fuente}

Código 15 de los Estados Unidos secciones 2601 a 2671. 